Bangladesh J. Bot. 49(1): 105-112, 2020 (March)

\title{
GENETIC ANALYSIS OF EXOTIC GERMPLASMS OF POMEGRANATE (PUNICA GRANATUM L.)
}

\author{
Suparna Sinha*, Dinesh Singh Thakur ${ }^{1}$, Manoj Kundu and Feza Ahmad \\ Department of Horticulture (F\&FT), BAU, Sabour, Bhagalpur, Bihar-813210, India
}

Keywords: Factor analysis, Genetic diversity, Heritability, Pomegranate

\begin{abstract}
Twenty exotic pomegranate (Punica granatum L.) germplasms were studied to determine the genetic parameters to understand the usefulness of genotypes in the breeding program. Forty characteristics were measured in fruits, arils, leaves, and flowers, as well as juice characteristics including, total soluble solids, titratable acidity, sugars, anthocyanin, and phenols. Analysis of variance establishes that among all the parameters analyzed, a significant genetic difference was present for yield and yield attribution traits of the studied pomegranate germplasm. All plants were grouped into five clusters among them Green Globe and Hakubotan were most distinct from others. Saharnyi, Orange, Ovadan, Nusai, Kaim-anar, Al-Sirin-Nar, 20090265, Eve and Sogdiana may be used as one of the parent with another parent Green Globe for getting better recombinants by hybridization method. The presence of significant inter-cluster variations revealed that hybridization program could be useful for the development of better plant type by using this pomegranate germplasms. Factor analysis exhibits that fruit weight shown to have the highest different value in the tested pomegranate germplasms so that this trait can be used for the separation and selection of pomegranate germplasms.
\end{abstract}

\section{Introduction}

Pomegranate (Punica granatum L.) is the tenth valuable fruits that consumed annually in the world. It has been cultivated extensively in Iran, India and some regions in the U.S.A (California), China, Japan, Spain, and Russia (Hazbavi 2014). India is the world's largest producer of pomegranates, and occupies third position regarding global export share. Pomegranate grew throughout India, but due to its better adaptability towards arid climate, the commercial cultivation mainly done in Maharashtra, Karnataka, Gujarat, Andhra Pradesh, Telangana, Madhya Pradesh, Tamil Nadu and Rajasthan. Pomegranate has the significant potential for diversification and commercial cultivation in Himachal Pradesh in recent years despite the fact that varietal array favoring cooler climate is narrow, also simultaneously solving the problem of global warming which adversely affects apple cultivation in the lower hills of North India.

The total pomegranate production in India was 2795 thousand MT in 2017-18. Plant genetic resources are the basis of fruit crop improvement. Though the pomegranate improvement work started as early as 1905 in India, it took a long time to commence with concentrated efforts on genetic improvement. The evaluation of genetic variability is the first step in any breeding program, and the progress depends on the level/degree/magnitude of genetic variability present in the population. However, a few reports are available about extent of variability in pomegranate on various quantitative characters. Since most of the economically relevant traits in plants are polygenic and profoundly influenced by environmental fluctuations, therefore, it is difficult to judge whether the observed variability is due to environment or genetic. Some yield attributing characters influence complex traits like the yield. Thus the extent of genetic variability

*Author for correspondence: <s.sinha.coh@gmail.com>. ${ }^{1}$ Department of Fruit Science, Dr. Y.S. Parmar University of Horticulture \& Forestry, Nauni, Solan, Himachal Pradesh-173230, India. 
existing for these traits are essential as the heritable components of variation are responsive to selection. It is merely reported that morphological characteristics of the fruit for identification of pomegranate genotypes are useful (Zamani 1990). However, these traits are significantly affected by environment and cultivation conditions and often do not result in sufficient discrimination between them (Kumar 1999).

Zaouay and Mars (2014) worked out the high heritability values along with genetic advances in fruit weight, skin color, juice color, and titratable acidity suggested that there were significant additive gene effects for such traits. Singh et al. (2010) observed high heritability values for acidity followed by fruit weight, the number of arils and yield/plant.

The present study evaluates the morphological variation among the exotic pomegranate collection and the genetic potentiality for the further improvement program.

\section{Materials and Methods}

The present research was carried out in the Experimental farm of Fruit Science, Dr. Y. S. Parmar University of Horticulture and Forestry, Nauni, Solan (Himachal Pradesh, India) during 2013. The experimental site is located at $1220 \mathrm{~m}$ above mean sea level and situated at $31^{\circ} \mathrm{N}$ latitude and $77^{\circ} \mathrm{E}$ longitude with average annual precipitation of $3.50-184.30 \mathrm{~mm}$.

Five years old 20 pomegranate germplasm accessions, namely Parfyanets, Saharnyi, Loulou, Nusai, Cloud, Green Globe, Podarok, Crab, Al-sirin-nar, Purple Heart, Kaim-anar, 20090265, Gulyalek, Haku-botan, Alk Pust Ghermez Saveh, Eve, Dewey, Ovadan, Sogdiana and Orange which were introduced from USDA-ARS, National Clonal Germplasm Repository, University of California, Davis USA during the year 2008 - 09 were used.

The trial was laid out under randomized block design with three uniform replications (one from each replication). Plants were selected for recording the observations. Intercultural operations were frequently done for getting better growth and yield. Straw mulch was applied around the pomegranate plants to save soil moisture and to restrict weed populations. Irrigation was applied at weekly intervals to maintain right moisture for better growth and development of plants. Plant protection means were also applied uniformly for all the plots during the period of the experiment. Five representative fruits were taken in each replicates at optimum maturity.

Observations were recorded for 40 morphological traits during flowering, growth condition of the plant, fruits, and quality traits (Table 1). The coefficient of variability was calculated as per the methodology suggested by Burton and de Vane (1953). Genetic gain was calculated as suggested by Johnson et al. (1955). Mean values recorded for each character were used to perform factor analysis and clustering to genotypes into similarity groups using Ward's method. Data processing was performed utilizing SPSS software (version 10).

\section{Results and Discussion}

A wide range of variation in mean value was found in yield, quality and yield attributing characters. Analysis of variance estimation showed significant genetic variability for all the traits recorded in the experiment (Table 1). The phenotypic coefficients of variation (PCV) for all the characters were slightly higher valued except (height of plant, number of stems, leaf breadth, petiole length, flower length, stamen length, aril breadth, fruit length and TSS/acidity ratio) than the corresponding genotypic coefficients of variation (GCV) values. The PCV and GCV value were recorded maximum for yield per plant, followed by some suckers per plant, flowering duration, and anthocyanin content in aril, fruit weight and TSS/acidity ratio. 
Table 1. Variability parameters for growth, flowering, fruiting, fruit and aril of pomegranate germplasm accessions.

\begin{tabular}{|c|c|c|c|c|c|c|}
\hline Characters & Mean & Range & $\begin{array}{l}\text { Genotypic } \\
\text { coefficients } \\
\text { of variation }\end{array}$ & $\begin{array}{l}\text { Phenotypic } \\
\text { coefficients } \\
\text { of variation }\end{array}$ & $\begin{array}{l}\text { Heritability } \\
\% \text { (broad } \\
\text { sense) }\end{array}$ & $\begin{array}{l}\text { Genetic } \\
\text { advance as } \\
5 \% \text { of mean }\end{array}$ \\
\hline Height of plant (m) & 2.13 & $1.35-3.18$ & 21.33 & 30.96 & 47.46 & 30.27 \\
\hline $\mathrm{N}-\mathrm{S}$ spread $(\mathrm{m})^{* *}$ & 1.50 & $0.45-2.65$ & 43.14 & 43.58 & 88.98 & 87.97 \\
\hline E-W spread $(\mathrm{m})^{* * *}$ & 1.38 & $0.34-2.54$ & 48.11 & 48.74 & 87.43 & 97.82 \\
\hline Stem girth $(\mathrm{m})$ & 49.63 & 20.11-96.09 & 45.71 & 45.74 & 99.78 & 94.11 \\
\hline Number of stems & 2.05 & $1.00-3.33$ & 32.43 & 40.94 & 62.76 & 1.66 \\
\hline Number of suckers/plant & 3.85 & $0.67-28.67$ & 83.17 & 83.25 & 96.06 & 171.14 \\
\hline Thorn length (mm) & 6.83 & $0-10$ & 40.25 & 40.28 & 99.38 & 82.84 \\
\hline Length of internodes $(\mathrm{cm})$ & 3.03 & $2.03-4.32$ & 16.30 & 16.62 & 96.26 & 32.95 \\
\hline Leaf length (mm) & 65.24 & $36.53-96.43$ & 22.73 & 22.92 & 98.38 & 46.44 \\
\hline Leaf breadth (mm) & 17.70 & $7.57-23.74$ & 18.59 & 28.11 & 43.7 & 25.31 \\
\hline Leaf area $\left(\mathrm{cm}^{2}\right)$ & 15.35 & $5.44-27.75$ & 41.07 & 41.09 & 99.93 & 84.57 \\
\hline Petole length (mm) & 6.01 & $3.27-10.01$ & 18.91 & 49.61 & 14.53 & 14.85 \\
\hline Flower length (mm) & 35.68 & $27.11-44.35$ & 11.90 & 17.10 & 48.43 & 17.06 \\
\hline Flower dia (mm) & 14.83 & $9.71-24.90$ & 21.75 & 25.27 & 74.07 & 38.57 \\
\hline Sapal size $\left(\mathrm{mm}^{2}\right)$ & 99.25 & $74.65-160.16$ & 19.77 & 19.79 & 99.97 & 40.68 \\
\hline Petal size $\left(\mathrm{mm}^{2}\right)$ & 456.87 & $361.54-647.24$ & 15.52 & 15.65 & 98.35 & 31.70 \\
\hline Stamen number & 336.73 & $234.33-751$ & 38.94 & 39.18 & 98.77 & 79.72 \\
\hline Stamen length (mm) & 7.99 & $5.81-9.71$ & 9.26 & 18.90 & 26.76 & 9.87 \\
\hline Flowering duration (days) & 55.52 & $40-195$ & 60.04 & 60.30 & 99.11 & 97.19 \\
\hline Arils/ fruit & 434.37 & $286.87-881.00$ & 34.63 & 34.66 & 99.86 & 71.30 \\
\hline Aril \% & 57.46 & $47.95-70.94$ & 10.60 & 10.78 & 96.79 & 21.49 \\
\hline Aril weight / fruit (g) & 116.41 & $73-186.27$ & 22.76 & 22.85 & 99.23 & 46.71 \\
\hline Aril/rind ratio & 1.68 & $1.12-2.55$ & 24.35 & 24.42 & 99.41 & 50.01 \\
\hline Aril length (mm) & 11.79 & $9.7-17.97$ & 13.31 & 14.766 & 81.25 & 24.72 \\
\hline Aril breadth (mm) & 6.86 & $5.50-12.59$ & 17.03 & 27.59 & 38.10 & 21.66 \\
\hline 100 arils weight $(\mathrm{g})$ & 28.25 & $12.51-41.11$ & 26.38 & 26.58 & 98.51 & 53.94 \\
\hline Fruit weight (g) & 202.78 & $144.56-275.84$ & 49.76 & 49.93 & 98.40 & 79.41 \\
\hline Fruit length (mm) & 64.99 & $55.19-76.35$ & 5.84 & 21.17 & 23.06 & 5.78 \\
\hline Fruit breadth (mm) & 73.54 & $64.27-94.13$ & 10.62 & 10.84 & 96.02 & 21.44 \\
\hline Rind thickness (mm) & 2.59 & $2.14-3.56$ & 18.86 & 19.10 & 97.5 & 38.36 \\
\hline Yield/ plant (kg) & 3.85 & $1.11-13.60$ & 166.89 & 167.12 & 99.79 & 330.71 \\
\hline Juice $\%$ & 47.64 & $34.37-70.41$ & 23.35 & 23.40 & 99.57 & 48.00 \\
\hline $\operatorname{TSS} \%^{*}$ & 13.75 & $9.93-15.37$ & 10.27 & 10.80 & 90.48 & 20.12 \\
\hline Acidity $\%$ & 1.43 & $0.66-2.26$ & 38.71 & 38.79 & 99.58 & 40.25 \\
\hline Total sugars & 9.90 & $7.55-14.13$ & 20.78 & 20.87 & 99.16 & 42.66 \\
\hline Reducing sugars & 8.23 & $6.27-12.51$ & 23.76 & 23.99 & 98.05 & 48.47 \\
\hline Non-reducing sugars & 1.63 & $1.04-2.34$ & 23.79 & 23.99 & 98.37 & 48.61 \\
\hline TSS/acidity ratio & 11.90 & $5.66-23.30$ & 49.25 & 59.70 & 68.07 & 83.71 \\
\hline Anthocyanin (mg/100 gm) & 15.23 & $3.23-30.60$ & 57.87 & 58.15 & 99.05 & 118.65 \\
\hline Phenols (mg/100 gm) & 619.59 & $308.03-981.24$ & 32.83 & 32.85 & 99.84 & 67.57 \\
\hline
\end{tabular}

TSS $*=$ Total soluble solids, N-S**= North-South and E-W ***= East-West. 
The progress of a breeding program was controlled by the magnitude and the nature of the genotypic and non-genotypic variation present. Since most of the economic traits (e.g., yield) are quantitative and are significantly affected by various environmental conditions, the study of heritability and genetic advance as a percentage of the mean is beneficial to determine the chance for improvement by selection which was already confirmed by Ali et al. (2003) and Vaghela et al. (2009). Heritability figure shows the reliability with which its phenotypic expression will recognize the genotype. However, GCV helps to measure the genetic variability in character, it is not possible to partition the heritable variation with this alone. Burton (1952) suggested that GCV together with heritability judge the best results of the amount of genetic advance to be required for a selection. The magnitude of heritability indicated the reliability of the genotypes with which they can be identified for their phenotypic expression.

The degree of heritability $\left(\mathrm{h}^{2}\right)$ was also estimated for all the characters under the experiment. Among 40 different characters under the study, heritability was recorded more than $90 \%$ for 27 characters (viz. Juice\%, TSS\%, acidity, total sugars, reducing sugars, non-reducing sugars, anthocyanin, phenols, yield, aril/fruit, aril\%, aril weight/fruit, aril: rind ratio, 100 aril weight, fruit weight, fruit breadth, rind thickness, sepal size, petal size, stamen numbers, flowering duration, leaf length, leaf area, girth stem, number of suckers, thorn length, and length of internodes). The high magnitude of broad sense heritability indicated that large proportion of phenotypic variance was attributed to the genotypic variance and that difference for these characters among the germplasm was real, characters were less influenced by the environment, and selection of these characters would be sufficient. Comparatively lower heritability was observed for the character TSS: acidity ratio $(68.07 \%)$.

Factor analysis was used to determine the number of significant factors to reduce the number of operating characteristics to discriminate between genotypes (Table 2). In the present study, the characteristics of plants, fruits, and arils are described in five major factors accounting $82 \%$ of total variations. For each factor, a factor loading of greater than 0.220 was assumed as being significant. For the first factor, characteristics including TSS, total sugars, TSS: acid ratio, yield, 100 aril weight, fruit weight, fruit length and other characteristics had a loading of more than 0.220 and defined $28.59 \%$ of the overall variance. The fruit breadth, rind thickness, flowering duration, leaf length and length of internodes were significant for the second factor governing $23.21 \%$ of the overall variance. The 3 rd factor with $13.59 \%$ of the overall variance contributed to characteristics such as acidity, phenols, aril weight per fruit and leaf breadth. The combination of fruit weight, fruits length, 100 aril weight, total soluble sugars, reducing sugar, TSS/acidity ratio, TSS\%, juice\%, and fruit yield/plant attributed $28.59 \%$ of the total variation and were, consequently, useful for genetic characterization of mentioned pomegranate germplasm.

The 20 pomegranate germplasms were grouped according to 5 factors into 5 clusters by Ward's method (Fig. 1). The dissimilarity level ranged from 1 to 120 , indicating that there were germplasms that were either very near or very different from each other. Genetic divergence of 20 pomegranate germplasms assessed with Ward's method revealed that the inter-cluster distances were longer than the intra-cluster indicating a more extensive genetic diversity between genotypes of the cluster on characteristics considered. Cluster 3 (Saharnyi, Orange, Ovadan, Nusai, Kaimanar, Al-Sirin-Nar, 20090265, Eve, Sogdiana) was the largest with nine germplasms, followed by cluster 1 (Parfyanets, Podarok, Dewey, Loulou, Crab, Gulyalek) with 5 germplasms, whereas, cluster 2, 4 and 5 included three (viz., Cloud, Alk Pust Ghermez Saveh, Purple Heart), one (Hakubotan) and one (Green Globe) germplasms, respectively. The maximum value of (59.47) intra-cluster distance was in the cluster 1 (Table 3). It apparently indicates that cluster 1 has genotypes that are relatively distant from each other than the other clusters which have lower Euclidean $^{2}$ distances except cluster 4 and 5 , which had only one accession. The highest inter- 
cluster distance was observed between germplasm of clusters 4 and 5 (181.49) followed by clusters 3 and 5 (169.9).

Table 2. Eigen values and cumulative variance for five major factors obtained from factor analysis and the characteristics of each factor for pomegranate germplasm.

\begin{tabular}{|c|c|c|c|c|c|}
\hline & 1 Vector & 2 Vector & 3 Vector & 4 Vector & 5 Vector \\
\hline Eigen value (Root) & 11.438 & 9.287 & 5.438 & 3.954 & 2.519 \\
\hline$\%$ var. exp. & 28.594 & 23.219 & 13.596 & 9.884 & 6.297 \\
\hline Cum. var. exp. & 28.594 & 51.813 & 65.409 & 75.293 & 81.590 \\
\hline Height of plant (m) & -0.122 & 0.089 & $-0.342 *$ & -0.103 & -0.060 \\
\hline N-s sperad (m) & 0.213 & -0.151 & 0.064 & 0.012 & $-0.239^{*}$ \\
\hline E-w (m) & -0.103 & -0.107 & 0.010 & $0.277 *$ & 0.155 \\
\hline Girth of stem (mm) & -0.062 & 0.082 & -0.036 & 0.212 & -0.114 \\
\hline Numbers of stems & 0.131 & -0.065 & -0.125 & 0.027 & -0.130 \\
\hline Number of suckers & 0.007 & 0.046 & -0.052 & -0.040 & -0.189 \\
\hline Thorn length (mm) & -0.166 & 0.068 & 0.074 & 0.193 & 0.154 \\
\hline Length of internodes $(\mathrm{cm})$ & 0.057 & $0.267^{*}$ & 0.060 & -0.020 & 0.074 \\
\hline Leaf length (mm) & -0.061 & $0.283^{*}$ & -0.134 & 0.044 & 0.053 \\
\hline Leaf bradth (mm) & -0.056 & 0.039 & $0.369 *$ & 0.053 & -0.091 \\
\hline Leaf area $\left(\mathrm{cm}^{2}\right)$ & $0.257 *$ & 0.045 & -0.040 & -0.192 & -0.217 \\
\hline Petole length (mm) & -0.105 & -0.125 & -0.038 & $0.352 *$ & 0.214 \\
\hline Flower length (mm) & $-0.247^{*}$ & -0.070 & 0.020 & -0.084 & 0.072 \\
\hline Flower dia (mm) & -0.072 & -0.012 & $-0.361^{*}$ & -0.001 & -0.084 \\
\hline Sepal size $\left(\mathrm{mm}^{2}\right)$ & -0.042 & $-0.282^{*}$ & 0.012 & 0.007 & -0.070 \\
\hline Petal size $\left(\mathrm{mm}^{2}\right)$ & -0.029 & $0.299^{*}$ & -0.135 & 0.084 & 0.042 \\
\hline Stamen Nos. & -0.024 & $-0.291^{*}$ & 0.099 & -0.161 & -0.031 \\
\hline Stamen length (mm) & -0.113 & -0.176 & $0.229 *$ & 0.114 & -0.204 \\
\hline Flowering duration & -0.023 & $0.300^{*}$ & -0.131 & 0.087 & 0.032 \\
\hline Arils/ fruit & -0.058 & -0.197 & -0.211 & $0.238 *$ & -0.060 \\
\hline Aril \% & -0.217 & -0.074 & -0.074 & -0.187 & $0.232 *$ \\
\hline Aril weight/ fruit (g) & -0.038 & -0.063 & $0.294 *$ & 0.169 & 0.214 \\
\hline Aril/ rind ratio & 0.219 & 0.072 & 0.039 & -0.060 & $0.222^{*}$ \\
\hline Aril length (mm) & 0.072 & -0.209 & -0.093 & -0.008 & $0.315^{*}$ \\
\hline Breadth (mm) & 0.200 & -0.057 & -0.199 & $0.221 *$ & -0.132 \\
\hline 100 arils weight $(\mathrm{g})$ & $0.228 *$ & -0.072 & -0.102 & -0.158 & -0.081 \\
\hline Fruit weight (g) & $0.375^{*}$ & 0.053 & -0.115 & -0.016 & 0.032 \\
\hline Fruit length (mm) & $0.237^{*}$ & 0.203 & 0.134 & -0.159 & -0.013 \\
\hline Fruit breadth $(\mathrm{mm})$ & 0.138 & $0.268^{*}$ & 0.202 & 0.071 & -0.144 \\
\hline Rind thickness (mm) & -0.070 & -0.070 & $0.232 *$ & 0.129 & -0.112 \\
\hline Yield/ plant kg & $0.234^{*}$ & $0.234 *$ & 0.016 & 0.153 & -0.041 \\
\hline Juice $\%$ & $0.229^{*}$ & $0.229^{*}$ & 0.029 & 0.018 & 0.189 \\
\hline $\operatorname{TSS}(\%)$ & $0.237^{*}$ & $0.237^{*}$ & 0.025 & 0.073 & -0.071 \\
\hline Acidity (\%) & -0.187 & -0.187 & -0.053 & $0.247 *$ & -0.062 \\
\hline Total sugars & $0.233^{*}$ & $0.233^{*}$ & 0.075 & -0.059 & -0.169 \\
\hline Reducing sugars & $0.266^{*}$ & $0.266^{*}$ & 0.052 & -0.043 & -0.073 \\
\hline Non-reducing sugar & -0.109 & -0.109 & 0.008 & -0.007 & 0.214 \\
\hline TSS/acidity ratio & $0.233^{*}$ & $0.233^{*}$ & 0.094 & -0.054 & -0.021 \\
\hline Anthocyanin (mg/100g) & -0.188 & -0.188 & 0.026 & -0.071 & 0.218 \\
\hline Phenols $(\mathrm{mg} / 100 \mathrm{~g})$ & -0.132 & $-\underline{0.132}$ & $\underline{0.027}$ & $\underline{0.263 *}$ & $-\underline{0.216}$ \\
\hline
\end{tabular}


Analysis of variance results revealed that high magnitude of genetic variability existed for the fruit yield per plant and others, offering a good opportunity for improvement through selection. The same agrees with the findings of Samadia and Pareek (2006).

High magnitude of broad sense heritability indicated that large proportion of phenotypic variance was attributed to the genotypic variance and that difference for these characters among the accessions was real. Also, the environment less influenced characters and selection of these characters would be effective. Earlier, Singh et al. (2010) reported high heritability values for characters such as acidity, fruit weight, some arils and yield/plant. The results drawn from the present investigation are in agreement with the findings of the above workers. The heritability estimates for different characters depending upon the genetic makeup of the breeding materials investigated. Therefore, knowledge about these measures in the materials in which breeders are focused is of high relevance.

Table 3. Average intra- and inter-Euclidean ${ }^{2}$ cluster distance (Ward's method) matrix of pomegranate germplasm.

\begin{tabular}{lccccc}
\hline & 1 Cluster & 2 Cluster & 3 Cluster & 4 Cluster & 5 Cluster \\
\hline 1 Cluster & 59.467 & 78.474 & 68.881 & 117.458 & 134.761 \\
2 Cluster & & 59.406 & 73.051 & 149.618 & 155.980 \\
3 Cluster & & 49.743 & 121.516 & 169.921 \\
4 Cluster & & & 0 & 181.488 \\
5 Cluster & & & & & 0.000 \\
\hline
\end{tabular}

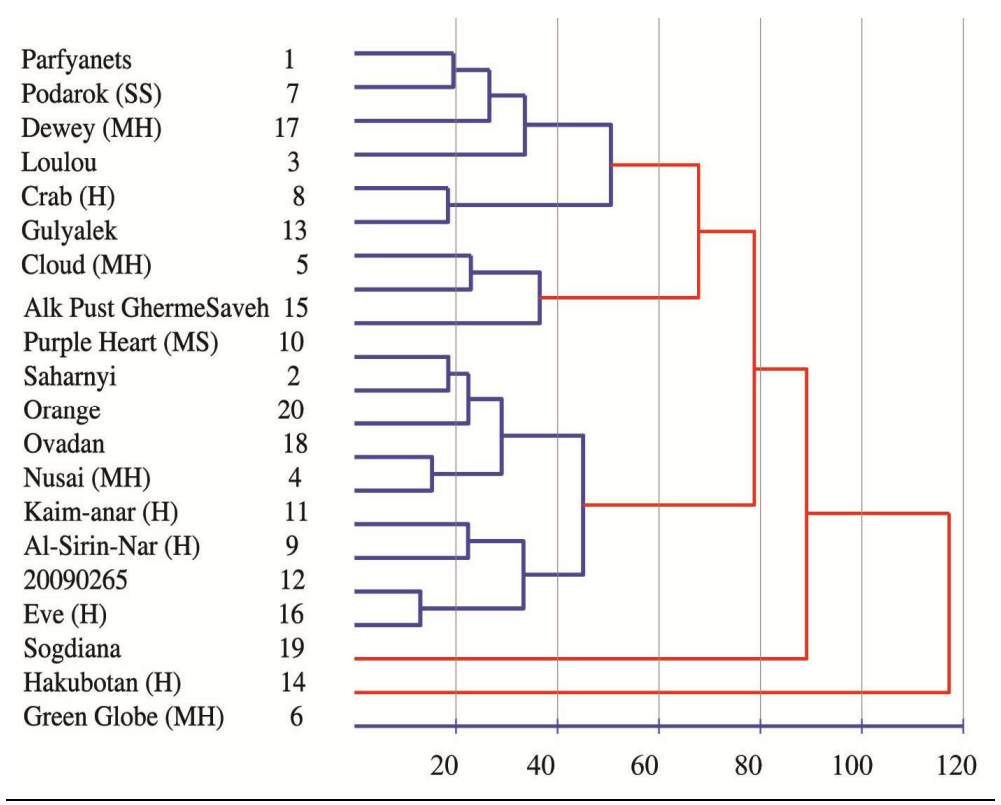

Fig. 1. Dendrogram of grouping 20 pomegranate accessions based on five main factors (Table 2) and Ward's method. 
According to Kandil et al. (2012), a selection based on phenotypically variations of the traits based on heritability estimates and strong GCV values would be better at predicting the effects of selection than with heritability values alone. The high values of heritability coupled with high GCV and expected genetic gain as a percentage of the mean were observed for yield/plant, some suckers and anthocyanin content, flowering duration, stem girth, leaf area, thorn length, stamen number, and fruit weight. It might be attributed to additive gene action controlling their expression and phenotypic selection for their amelioration could be brought about by methods like mass selection or bulk method after hybridization in early generations. The present results are in agreement with those of Mir et al. (2006).

Principal components analysis (PCA) is a useful statistical technique for providing a better comprehension of the relationships, correlations, and significance among variables studied. When applied to germplasm collections, PCA shows the structure of the collection by identifying the most relevant variables relationships among germplasm and possible outliers (Moraes et al. 2013). For example, Karimi and Mirdehghan (2013) in Iran characterized economically crucial local pomegranate cultivars on their fruit diameter, fruit weight, fruit length, peel weight, peel thickness, seed length, seed diameter, seed firmness, and calyx diameter.

Factor analysis exhibits that the traits of the fruits provided the primary factor, confirming $28.59 \%$ of the total variance, which must be taken into examination when differentiating between pomegranate germplasm. Fruit weight was shown to have the highest different value in the tested pomegranate germplasm; therefore this trait can be used for the separation and selection of pomegranate germplasm.

Maximum inter-cluster distance is indicative that germplasm falling in these clusters had wide diversity and can be used for hybridization program to get better recombinants in the segregating generations. Different intra- and inter-cluster distances were recorded previously for various fruit crops like pomegranate, walnut, almond and pecan cultivars (Akbarpour et al. 2010).

Significant genetic variation was present for yield and yield attribution traits for exotic germplasm of pomegranate understudy. The results of this study may help in developing strategies for pomegranate breeding program to have better varieties regarding quality and yield. The combination of fruit weight, fruits length, 100 aril weight, total soluble sugars, reducing sugar, TSS/acidity ratio, TSS $\%$, juice $\%$, and fruit yield/plant attributed $28.59 \%$ of total variation. All plants were grouped into five clusters among them Green Globe and Hakubotan were most distinct from others. However, significant inter-cluster variations revealed that hybridization program could be useful for the development of better plant type.

\section{References}

Akbarpour V, Hemmati K, Sharifani M and Sadr ZB 2010. Multivariate analysis of physical and chemical characteristics in some pomegranate (Punica granatum L.) cultivars of Iran. Journal of Food Agriculture and Environment 48: 244-248.

Ali N, Javidfar F, Elmira JY, Mirza MY 2003. Relationship among yield components and selection criteria for yield improvement in winter rapeseed (Brassica napus L.). Pakistan Journal of Botony 35(2): 167174.

Burton GW 1952. Quantitative inheritance in grasses In Proceedings of 6th International Grassland Congress 1: 277-283.

Burton GW and DeVane EH 1953. Estimating heritability in tall fescue (Festuca arundinacea) from replicated clonal material. Agronomy Journal 45: 478-481.

Hazbavi I 2014. Using geometrical characteristics to regarding pomegranate fruit (var Malas). International Journal of Biosciences 4(7): 100-105. 
Johnson HW, Robinson HF and Comstock RE 1955. Estimates of genetic and environmental variability in soybeans. Agronomy Journal 47: 314-318.

Kandil AA 2012. Multivariate analysis of some economic characters in flax. Pakistan Journal of Biological Sciences 15: 85-91.

Karimi HR and Mirdehghan SH 2013. Correlation between the morphological characters of pomegranate (Punica granatum L.) traits and their implications for breeding. Turkish Journal of Botany 37: 355-362.

Kumar LS 1999. DNA markers in plant improvement. Biotechnology Advances 17: 143-183.

Mir MM, Sofi AA, Ahmad MF and Umar I 2010. Variability pattern in different morphological characters of pomegranate under karewa belts of Kashmir. Indian Journal of Horticulture 67: 47-50.

De Moraes MR, Daiuto ER, Vietes RL, Cardoso NC and Smith RE 2013. Effect of active modified atmospheres on the quality of non-astringent persimmons (Caqui Giombo) D. kaki Thunb, When stored under refrigerated conditions. Advance in Horticultural Science 27: 73-80.

Samadia DK and Pareek OP 2006. Fruit quality improvement in pomegranate under hot arid environment. Indian Journal of Horticulture 63(2): 126-132.

Singh D, Sharma N and Kumar K 2010. Assessment of phenotypic variability, its heritable components and character association in pomegranate (Punica granatum) genotypes. Indian Journal of Agricultural Sciences 80: 667-672.

Vaghela MD, Poshiya VK, Savalixa JJ, Kavani RH and Davada BK 2009. Genetic variability studies in kabuli chickpea (Cicer arietinum L.). Legume Research 32(3):191-194.

Zamani Z 1990. Characteristics of pomegranate cultivars grown in Saveh of Iran (in Farsi). M.Sc. Thesis, University of Tehran, Tehran, Iran.

Zaouay F and Mars M 2014. Phenotypic variation and estimation of genetic parameters to improve fruit quality in Tunisian pomegranate (Punica granatum L.) accessions. The Journal of Horticultural Science and Biotechnology 89(2): 221-228.

(Manuscript received on 17 September, 2018; revised on 9 May, 2019) 